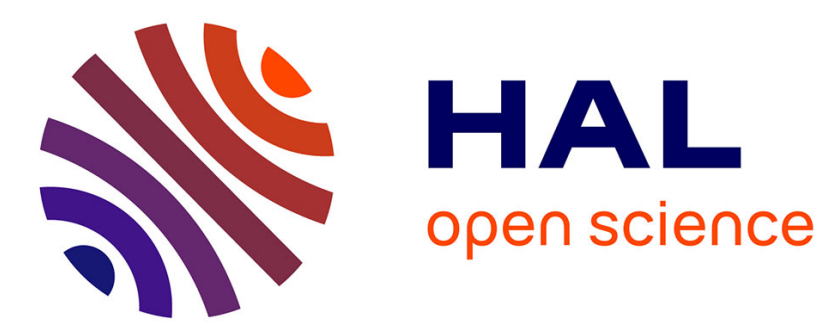

\title{
Understanding project complexity: implications on project management
}

Ludovic-Alexandre Vidal, Franck Marle

\section{To cite this version:}

Ludovic-Alexandre Vidal, Franck Marle. Understanding project complexity: implications on project management. Kybernetes, 2008, 10.1108/03684920810884928 . hal-01215364

\author{
HAL Id: hal-01215364 \\ https://hal.science/hal-01215364
}

Submitted on 14 Oct 2015

HAL is a multi-disciplinary open access archive for the deposit and dissemination of scientific research documents, whether they are published or not. The documents may come from teaching and research institutions in France or abroad, or from public or private research centers.
L'archive ouverte pluridisciplinaire HAL, est destinée au dépôt et à la diffusion de documents scientifiques de niveau recherche, publiés ou non, émanant des établissements d'enseignement et de recherche français ou étrangers, des laboratoires publics ou privés. 


\title{
Understanding project complexity
}

\section{Implications on project management}

\author{
Ludovic-Alexandre VIDAL ${ }^{1}$, Franck MARLE $E^{1}$
}

Ecole Centrale PARIS - Laboratoire Genie Industriel

Grande Voie des Vignes 92290 Chatenay-Malabry France

1.Ph.D. and teaching assistant-Corresponding author-ludovic-alexandre.vidal@ecp.fr

2. Doctor and assistant professor-franck.marle@ecp.fr

Research paper.

\begin{abstract}
Purpose

Better identify, define and model complexity within the field of project management in order to manage better under conditions of complexity (and manage better complexity-induced risks).
\end{abstract}

Design / Methodology / Approach

A large literature review enlightens the lack of consensus on project complexity and thus provides a broad view and a critical analysis of the underlying concepts. A project complexity framework and definition are then proposed. After underlining the stakes of project complexity in accordance with these proposals, a project complexity model is then built notably thanks to systems analysis. 


\section{Findings}

Proposal of standard project complexity framework and definition. Proposal of a synthesis of the relationships between the concepts of project uncertainty and project complexity. Proposal of a project complexity model (and validation thanks to industrial application).

Research limitations / implications

The literature review and project complexity framework tries to be exhaustive even though it is likely to be completed. The final version of the model is still to be computed and tested.

Practical implications

Avoid confusion when defining and managing a complex project, particularly between project team members (and as a consequence improve communication and information sharing). Better assess the propagation of a change within the project.

Originality / Value

The paper proposes an original framework and definition of project complexity. The complexity model permits the navigation from any element of the project to any other (when detail is needed) and is as a consequence original and complementary with traditional project management models and tools.

\section{KEYWORDS}

Project management, complexity, uncertainty, risk, modelling, systems analysis. 


\section{Introduction}

A project is a temporary and unique endeavour undertaken to deliver a result. This result is always a change in the organization, whatever it is in its processes, performance, products or services. This transformation consists then in a gap between a start and a final state. Time and resources are consumed to produce results, which may be deliverables and/or performance improvement and/or resource improvement (skills, knowledge). Each project is unique because there is always at least one of the following parameters that changes: targets, resources and environment. As projects became more and more present into organizations, and as they had bigger and bigger amounts at stake, it became impossible to let them live without specific and rigorous methodology. As a consequence, project management was created as a formalized and structured methodology. It is usually admitted than modern project management appeared during World War II and was initially dedicated to big military and construction projects.

Project management has then grown up and spread around the world to become what it is today, that is to say a set of theories, principles, methodologies and practices, sometimes included in standard body of knowledge as PMI (PMI, 2004) and IPMA (IPMA, 2006 a). The current vision tends to rely upon the notions of planning and control to propose models and prescriptions as ways to increase the ability of humans to control complex worlds (Stacey, 2001), (Wood, 2002). It emphasises the role of project actors regarding the issues of time, cost and scope (Cicmil and al., 2006).

For all practical purposes, lots of studies have been done, based on statistical calculations or surveys. Their conclusion is that current methods have shown their limits, since they cannot face anymore the stakes of ever growing project complexity. Limits and lacks have indeed been detected in research as well as in industry about the project predictability, since usual parameters (time, cost and quality) are clearly not sufficient to describe properly the complete situation at a given time (Meijer, 2002), (Jaafari, 2003), (Williams, 1999).

This articles aims then at describing the concept of project complexity thanks to a large literature review in order to understand what the underlying notions behind this concept are. It notably focuses on project complexity factors and builds an innovative and exhaustive project complexity framework that could be a reference for any project which has to face the complexity stakes. Finally, this article aims at proposing a definition of project 
complexity before having a look at the impacts of complexity on project management and studying how it can be modelled and analysed. It must be noted that the article discusses at several moments the links between the two concepts of complexity and uncertainty in order to make a clear distinction between them and therefore avoid confusion. Perspectives for future research work in this field are finally given.

\title{
Former research works on complexity and project complexity
}

\author{
Prerequisite for this section: the project system
}

According to systems analysis (Penalva, 1997), (Le Moigne, 1990), (Boulding, 1956), (Marle, 2002), (Vidal and al., 2007) a system is an object, which, in a given environment, aims at reaching some objectives (teleological aspect) by doing an activity (functional aspect) while its internal structure (ontological aspect) evolves through time (genetic aspect) without losing its own identity. Projects can thus be considered as systems. Indeed, a project exists within a specific environment and aims at reaching objectives given this context (teleological aspect). A project has to accomplish a network of activities using some methods and methodologies (functional aspect). A project has an internal structure composed of resources, deliverables, tools, workers, etc... (ontological aspect). Finally, a project evolves through time, via resource consumption, product delivery, members' changes and gain of experience, without losing its own identity (genetic aspect). As a consequence, in the following of this article, we consider projects as systems and thus study the field of complex systems to deal with project complexity.

\section{Complexity and project complexity}

Complexity is everywhere and is continuously growing, with an increasing pace. Research works on the concept of complexity have been conducted for years and have produced some interesting results and notions. There are historically two main scientific approaches of complexity (Schlindwein and al., 2005). The one, usually known as the field of descriptive complexity, considers complexity as an intrinsic property of a system, a vision which incited researchers to try to quantify or measure complexity. An example of this vision is the work of Baccarini (Baccarini, 1996). He considers project complexity through the concepts of technological complexity and 
organisational complexity. He regards them as the core components of project complexity which he tries to describe exhaustively. The other one, usually known as the field of perceived complexity, considers complexity as subjective, since the complexity of a system is improperly understood through the perception of an observer. Both approaches can apply to project complexity and project management complexity. For all practical purposes, a project manager deals with perceived complexity as he cannot understand and deal with the whole reality and complexity of the project. As a consequence, this article aims at creating a link between those two traditional visions of complexity. Knowing that one tries to cope with perceived complexity, this research aims at bridging the gap between perceived complexity and real complexity by defining, describing and modelling better real project complexity. This new frame of reference would enable anyone who shares this representation to perceive more properly the project reality.

The difficulty is that there is actually a lack of consensus on what project complexity really is. As Sinha and al. (Sinha and al., 2001) underline it, "there is no single concept of complexity that can adequately capture our intuitive notion of what the word ought to mean". Complexity can be understood in different ways not only in different fields but has also different connotations within the same field (Morel and al., 1999). However, Edmonds (Edmonds, 1999) proposes an overview of the concept of complexity within different fields and finally tries to give a generic definition of what complexity is: "Complexity is that property of a model which makes it difficult to formulate its overall behaviour in a given language, even when given reasonably complete information about its atomic components and their inter-relations". This definition, which is quite appropriate to encompass all the aspects of project complexity, emphasises that complexity is generally related to the way the project system is modelled. To some extent, the model is the first layer of the project perception, the second layer being the perception when understanding the project model.

According to Marle (Marle, 2002), who notably follows the concepts of Genelot (Genelot, 2001), it must be noted that complexity is the property of a system that causes on one hand the emergence of new properties that none of the elements of the system owns, and on the other hand the apparition of phenomena that could not be predicted thanks to the sole knowing, even complete, of the behaviour and interactions of the elements of the system. Complexity can thus have both a negative aspect (in terms of difficulty to be understood or contolled) and a positive influence on the project system (thanks to the emergence of opportunities). 
As a whole, whatever the vision of complexity one has, the project system can be considered as a complex system. However, some work is to be done to clarify the notion of project complexity in order to cope with it more efficiently. Due to the lack of consensus between the different visions and definitions of complexity, even though the manipulated concepts are sometimes very near, many research works tried to define and identify some key factors and drivers of project complexity, but there is no standardized and commonly-agreed list of project complexity drivers in the literature either. The next section aims at addressing the notion of project complexity in terms of its characteristics and factors in order to build a project complexity framework that could be a reference for any project.

\section{Project complexity factors and characteristics}

After a literature review on project management and project complexity (Baccarini, 1996), (Sinha and al., 2001), (Marle, 2002), (AFNOR), (IPMA, 2006 b), (Laurikkala and al., 2001), (Aissa, 2004) etc., we do argue that project complexity can be characterized through some factors that can be classified into four families (see Figure 1). All are necessary but non-sufficient conditions for project complexity. The first family encompasses project size factors. The second one gathers factors of project variety. The third one gathers those that are relative to the interdependencies and interrelations within the project system. Finally, the fourth one deals with project complexity context-dependence. In this section, we give a few words about them and then build a new project complexity framework according to this classification.

\section{Figure 1. Drivers of project complexity}

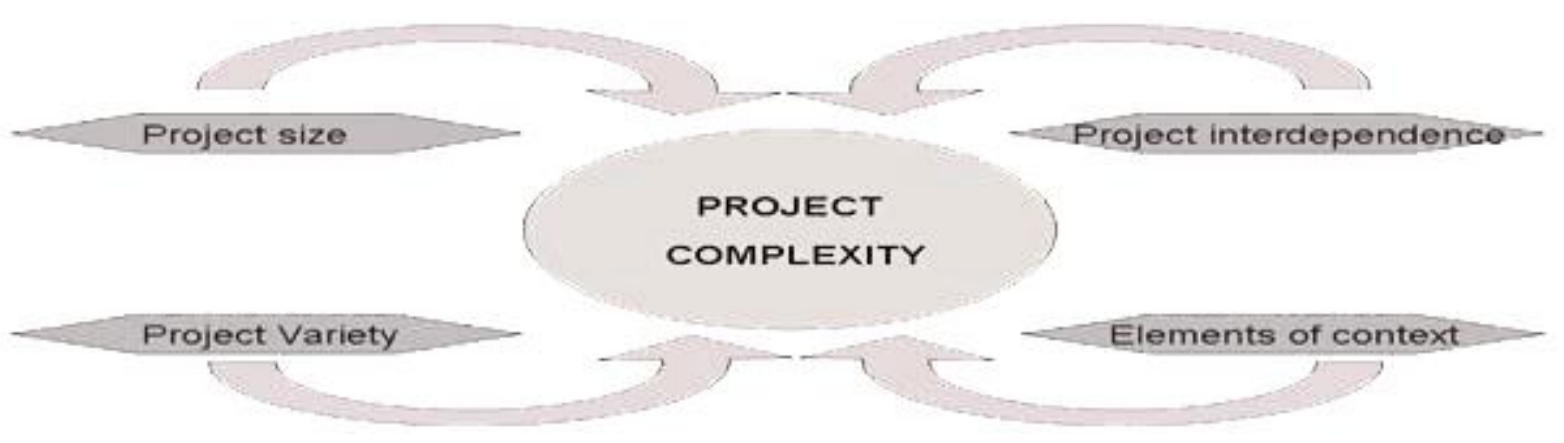


The size of the project system

The size of the project system appears to be a necessary condition for project complexity. For instance, a recent paper states that the organisational system should be over a minimum critical size to be considered as a complex system (Corbett and al., 2002). As a consequence, the size of the project system is a project complexity factor and identifying the parameters that characterize the size of the project system gives a first list of drivers of project complexity when one focuses on what project size means.

The variety of the project system

The project system variety appears to drive project complexity too. As mentioned by Sherwood and Anderson (Sherwood and al., 2005), "diversity relates closely to the number of emergent properties" and is a necessary condition for project complexity. As underlined by Corbett and al. (Corbett and al., 2002), "the one thing that comes through loud and clear is that complexity is tied up with variety, be it in the world of biology, physics or manufacturing. Moreover, it has something to do with how all of this variety interacts". This aspect of project complexity in terms of interactions and interdependencies within the project system exactly clings to the third family of project complexity factors which is described in the following paragraph.

Interdependencies within the project system

As underlined by several authors, interdependencies are likely to be the greatest drivers of project complexity. Rodrigues and al. (Rodrigues and al., 1996) explain that "experience suggests that the interrelationships between the project's components are more complex than is suggested by the traditional work breakdown structure of project network", suggesting that traditional project management tools cannot be sufficient to catch the reality of interdependence. This seems all the more problematic since "there is a complete interdependence between the components of the complexity: each element will depend and influence on the others" (Calinescu and al., 1998). 


\section{Context-dependence}

Chu and al. (Chu and al., 2003) underline that contextuality is an essential feature of complexity, considering it as a common denominator of any complex system. Project complexity context-dependence is also underlined by Koivu and al. (Koivu and al., 2004) who notably insist on the fact that "the context and practices that apply to one project are not directly transferable to other projects with different institutional and cultural configurations, which have to be taken into account in the processes of project management and leadership". As a consequence, project complexity cannot be neither analysed nor managed without considering the implications of the project context on it.

\section{Conclusion : building a project complexity framework.}

The broad literature review we carried out enabled us to build a project complexity framework that aims at being a reference for any project manager to identify and characterize some aspects of its project complexity, so that he can understand more efficiently the stakes of its project complexity management. Even though we had the ambition to be exhaustive, some others project complexity factors might be added to this framework. In addition to the classification of these factors according to the four families we identified, we use Baccarini's wellestablished dichotomy considering that project complexity is composed of technological complexity and organisational complexity.

Hereinafter, on Table I, the completed project complexity framework we have built thanks to this review is exposed. Even though the factors belonging to the family of interdependencies within the project system are hardly more numerous that the others, this class appears to be the most important for project complexity and dayto-day project management (Marle, 2002). Interactions management is likely to be both one of the causes of greatest value creation during the project and one of the riskiest parts of the project. Finally, it has to be noticed that approximately $70 \%$ of the identified complexity factors are related to organizational aspect, not technical. 
Table I. Project complexity framework : classification of project complexity factors

\begin{tabular}{|c|c|c|c|c|}
\hline & $\begin{array}{c}\text { Project System } \\
\text { Size }\end{array}$ & $\begin{array}{c}\text { Project System } \\
\text { Variety }\end{array}$ & $\begin{array}{c}\text { Interdependencies } \\
\text { within the project } \\
\text { system }\end{array}$ & $\begin{array}{l}\text { Elements of } \\
\text { context }\end{array}$ \\
\hline $\begin{array}{l}\text { Organisational } \\
\text { complexity }\end{array}$ & $\begin{array}{ll}\text { - } & \text { Duration of the } \\
\text { project } \\
\text { - } \\
\text { cargeness of } \\
\text { - } & \text { Number of investment } \\
\text { activities } \\
\text { - Number of } \\
\text { companies / } \\
\text { projects sharing } \\
\text { their resources } \\
\text { Number of } \\
\text { decisions to be } \\
\text { made } \\
\text { Number of } \\
\text { deliverables } \\
\text { Number of } \\
\text { departments } \\
\text { involved } \\
\text { Number of } \\
\text { hierarchical levels } \\
\text { Number of } \\
\text { information } \\
\text { systems } \\
\text { Number of } \\
\text { investors } \\
\text { Number of } \\
\text { objectives } \\
\text { Number of } \\
\text { stakeholders } \\
\text { Number of } \\
\text { structures / groups } \\
\text { / teams to be } \\
\text { coordinated } \\
\text { Staff quantity }\end{array}$ & $\begin{array}{ll}\text { - } & \begin{array}{l}\text { Diversity of staff } \\
\text { (experience, social }\end{array} \\
\text { span ...). } \\
\text { Geographic } \\
\text { location of the } \\
\text { stakeholders (and } \\
\text { their mutual } \\
\text { disaffection) } \\
\text { Variety of financial } \\
\text { resources } \\
\text { Variety of } \\
\text { hierarchical levels } \\
\text { within the } \\
\text { organisation } \\
\text { Variety of } \\
\text { information } \\
\text { systems to be } \\
\text { combined } \\
\text { Variety of } \\
\text { organisational } \\
\text { interdependencies } \\
\text { Variety of } \\
\text { organisational skills } \\
\text { needed } \\
\text { Variety of project } \\
\text { management } \\
\text { methods and tools } \\
\text { applied } \\
\text { Variety of the } \\
\text { interests of the } \\
\text { stakeholders } \\
\text { Variety of the } \\
\text { stakeholders' status }\end{array}$ & $\begin{array}{ll}\text { - } & \text { Availability of people, } \\
\text { material and of any } \\
\text { resources due to sharing } \\
\text { Combined transportation } \\
\text { Dependencies between } \\
\text { schedules } \\
\text { - } \begin{array}{l}\text { Dependencies with the } \\
\text { environment }\end{array} \\
\text { - } \begin{array}{l}\text { Dynamic and evolving } \\
\text { team structure }\end{array} \\
\text { Interconnectivity and } \\
\text { feedback loops in the task } \\
\text { and project networks } \\
\text { Interdependence between } \\
\text { actors } \\
\text { Interdependence between } \\
\text { sites, departments and } \\
\text { companies } \\
\text { Interdependence of } \\
\text { information systems } \\
\text { Interdependence of } \\
\text { objectives } \\
\text { Level of interrelations } \\
\text { between phases } \\
\text { Number of interfaces in } \\
\text { the project organization } \\
\text { Processes interdependence } \\
\text { Relations with permanent } \\
\text { organizations } \\
\text { Stakeholders interrelations } \\
\text { Team cooperation and } \\
\text { communication }\end{array}$ & 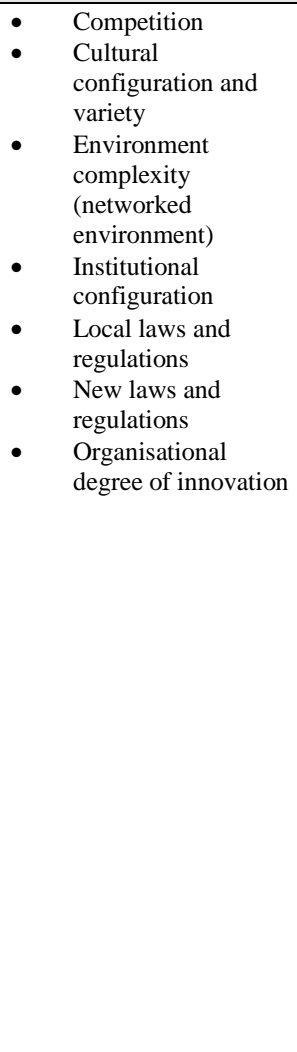 \\
\hline $\begin{array}{l}\text { Technological } \\
\text { complexity }\end{array}$ & $\begin{array}{ll}\text { - } & \text { Number and } \\
\text { quantity of } \\
\text { resources } \\
\text { - } \\
\text { Largeness of } \\
\text { scope (number of } \\
\text { components, } \\
\text { etc...) }\end{array}$ & $\begin{array}{ll}\text { - } & \text { Variety of } \\
\text { resources to be } \\
\text { manipulated } \\
\text { Variety of the } \\
\text { product } \\
\text { components } \\
\text { Variety of } \\
\text { technological } \\
\text { dependencies } \\
\text { Variety of } \\
\text { technological skills } \\
\text { needed } \\
\text { Variety of the } \\
\text { technologies used } \\
\text { during the project }\end{array}$ & 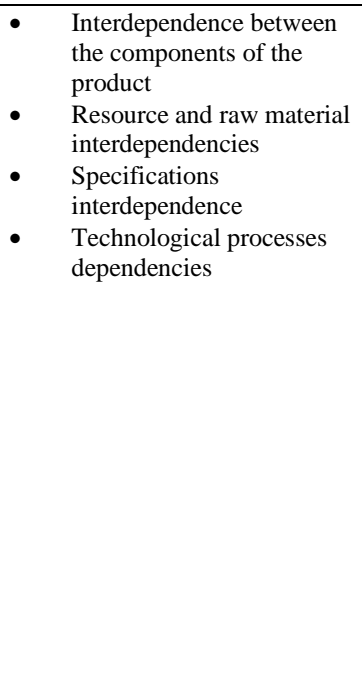 & 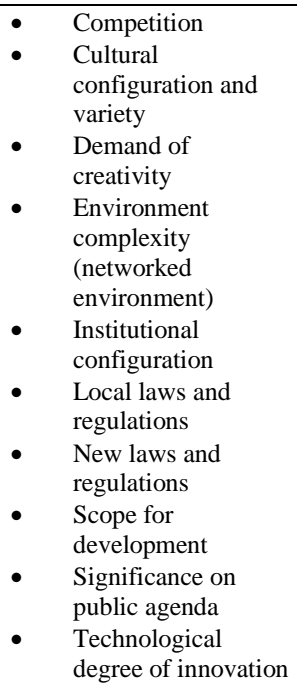 \\
\hline
\end{tabular}




\section{Proposing a definition of project complexity}

This state of the art being made, this framework being elaborated and the concepts being discussed, we now propose a definition of project complexity. We state that "project complexity is the property of a project which makes it difficult to understand, foresee and keep under control its overall behaviour, even when given reasonably complete information about the project system. Its drivers are factors related to project size, project variety, project interdependence and project context.”

Every aspect of systemics is part of the overall behaviour of the project system, which means that, according to this definition, project complexity is the property which makes it difficult to understand, foresee and keep under control any of these aspects. The reader is to keep in mind this definition until the end of this article as the next section aims at exploring the stakes of project complexity.

\section{The stakes of project complexity}

\section{Understanding the consequences of project complexity}

This section aims at describing some of the consequences of project complexity in order to understand the stakes of project complexity management and to characterize how it can be helpful to assist global project management. The links between project complexity, project risks, project uncertainty and project performance are still unclear in the academic world as well as in the industrial one. For instance, Parsons-Hann and Liu state that "it is clear that requirements complexity contributes to project failure in organisations, what is not apparent is to what degree this statement holds true". (Parsons-Hann and al., 2005)

Even if the relation between risks and complexity has to be clarified, complexity appears to be one of the main reasons of the unpredictability of projects, particularly in terms of problems and failures. As mentioned in the project complexity framework we have built, there is a high number and great diversity of objects to manage, with a high number and great diversity of parameters that characterize them. The amount and diversity of these 
interactions are so huge that project objects rapidly become unmanageable thanks to the sole use of classical tools and methods of project management. Both the complexity of the evolving environment and the internal complexity of the project justify the need for a new approach that would assist the existing ones.

The global issue of project complexity management is then for a project manager to know how to seize the opportunities emerging from complexity and to know how to avoid or at least diminish the negative effects of complexity. That is why we now focus on the main consequences of project complexity.

\section{Uncertainty as a consequence of project complexity}

Uncertainty appears as one of the possibly negative consequences of project complexity. This paragraph illustrates how project complexity can be a source of uncertainty, thus making a distinction between these two concepts as some research works argued for it before (Pich and al., 2007), (Little, 2005). In order to follow this paragraph more easily, the reader should refer to the drawn synthesis on Figure 2.

\section{Figure 2. Project complexity as a source of project uncertainty}

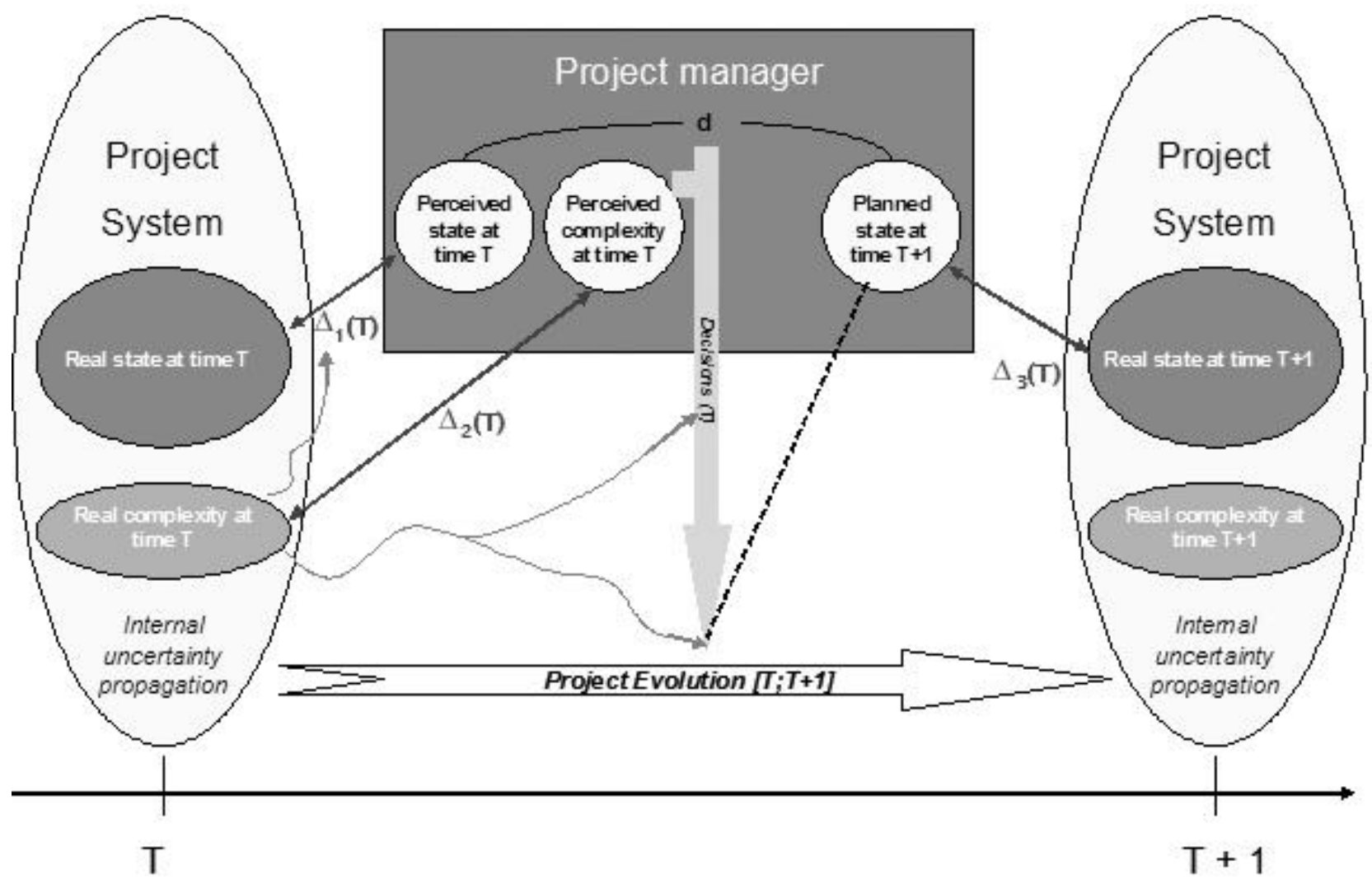


Let a project manager analyse a project system at a given time $\mathrm{T}$ in order to plan his decisions and actions for the next period to reach a state at time $\mathrm{T}+1$. The project system can be described by its real state at time $\mathrm{T}$, a state the real complexity of which can also be considered at time T. When analysing and monitoring the project system at time $\mathrm{T}$, the project manager first perceives the real state at time $\mathrm{T}$, introducing a difference (and thus a source of uncertainty) between the real project state at time $\mathrm{T}$ and the perceived project state at time $\mathrm{T}\left(\Delta_{1}(\mathrm{~T})\right)$.

This difference has two principal causes. On one hand, the project manager has its own culture and references, and thus, his perception of the project system alters reality. On the other hand, real project complexity implies that the project system cannot in essence be completely understood: by definition, there is always an irreducible residual source of uncertainty caused by complexity (mainly due to the high number and variety of elements and interactions that cannot be completely neither identified nor understood) when trying to identify the project system state. For the same reasons, there is a difference (and thus another source of uncertainty $\Delta_{2}(T)$ ) between perceived project complexity at time $\mathrm{T}$ and real project complexity at time $\mathrm{T}$.

This question of perception is approached by Jaafari (Jaafari, 2003) and appears to be a crucial issue for project complexity. Jaafari insists on the fact that individuals, depending on their mental models and representations, perceive the outside reality in their own way. As a consequence, project complexity is dealt with through a filter, which is the individual perception of the project system and environment (based on one's representations). In other terms, the difficulty is that the gaps $\Delta_{1}(\mathrm{~T})$ and $\Delta_{2}(\mathrm{~T})$ are different for any project team member as anyone has its own perception of reality. The leadership and adaptability of the project manager is thus crucial in order to try to share a common reference and perception of reality within the project team.

Let us now have an overall look at the global process of project management. The project manager analyses the state of the project at a given time $\mathrm{T}$ and considers the difference $\delta$ between this state at time $\mathrm{T}$ and the state he planned for the next period at time $\mathrm{T}+1$. The project manager then makes decisions under the constraints of project context and perceived complexity and does the corresponding actions to influence the project evolution in order to reach the planned state at time $\mathrm{T}+1$. This process is also altered by complexity-driven uncertainties. First, decisions can be directly altered by real project complexity. For instance, when transmitting some information about a decision, information can be altered because of cultural variety, staff diversity and staff 
interdependences. As a consequence, when turning this decision into an action (at the end of the information transmission process), the real action can be different from the action the project manager wanted. Moreover, real complexity has an influence on the impact of the decisions made and the subsequent actions done: the project manager deals with perceived (and not real) project complexity when making its decisions and moreover, real project complexity entails the project manager's inability to forecast efficiently both the impact of its decisions and the project evolution. As a whole, real project complexity is one of the causes of the difference between the planned state at time $\mathrm{T}+1$ and the real state at time $\mathrm{T}+1$, introducing another difference $\Delta_{3}(\mathrm{~T})$.

Finally, project complexity is also a source of uncertainty in terms of propagation. Indeed, let an uncertain parameter $\mathrm{P}$ be in the project system, meaning that the value of $\mathrm{P}$ is known under conditions of uncertainty $\mathrm{P}_{ \pm} \delta_{\mathrm{P}}$. (confidence interval). $\mathrm{P}$ can be for instance the duration of a task, the cost of a deliverable, or any dimension of any object of the project system. Since the project system is complex, it includes interdependencies and interconnectivities between its elements (tasks, resources,...). As a consequence, the corresponding uncertainty $\delta_{\mathrm{P}}$ on a parameter $\mathrm{P}$ can spread through the entire system, as any element in relation with parameter $\mathrm{P}$ faces uncertainty and transmits to all its neighbours in the same manner.

Uncertainty thus propagates through the entire project system of the complex nature of the project in terms of interaction. Uncertainty propagation is all the more complex to manage since a project, as any complex system, has a high number of various elements and interactions, meaning for example that uncertainty on the duration of a task $\mathrm{i}$ can be transmitted in terms of uncertainty on the duration of a task $\mathrm{j}$, which can be transmitted in terms of uncertainty on the cost of a deliverable $\mathrm{D}$, which can then be transmitted in terms of uncertainty on the quality of the global project outcome... In other terms, uncertainty propagation in the project system is even more complex since the project manager has to manage the change of the nature of uncertainty at each stage it is transmitted within the system.

Complexity-driven uncertainties are as a whole a major source of non-decidability and unpredictability for the project system, which is part of the core characteristic of our definition of project complexity (property of a project which confers the inability to understand, foresee and keep under control the project's overall behaviour). As a consequence, complexity-driven uncertainties are a major source of risks for the project. That is why the next section gives a rough-shape introduction about the more general concept of complexity-induced risks. 
First, we remind the reader that, because of the property of emergence, complexity can be a source of risks as well as a source of opportunities. The aspect of opportunity seizing is not dealt with in this article but the reader should keep in mind that complexity is not only a cause of problems. In other terms, no project manager should struggle for complexity reduction: the stake is to properly manage project complexity in order to avoid the negative aspects of it and seize at the same time the opportunities that it creates. For instance, when staffing the project, one should keep in mind aspects of complexity such as staff quantity (avoiding oversize,...) or staff diversity. Millhiser and Solow indeed explain for instance that an optimal level of interaction can be reached in order to make the best compromise between opportunity emergence and complexity induced risks (Millhiser and al., 2007). The concept of complexity induced risks is to be studied. We argue that two main classes of complexity induced risks can occur during a project.

The first class of them gathers all the risks which are directly induced by project complexity. The project complexity framework we have defined is a first basis to identify them. Even though this article does not deal with the elaboration of a methodology that would be used to identify these risks, the general idea of it is to focus on the complexity aspects that have been underlined (corresponding procedures are still to be defined). By paying attention to the key aspects of complexity that can be risky (for instance, some interfaces within the project system), the identification of this first class of complexity induced risks will enable one to complete the risk lists which are usually done thanks to traditional risk analysis methodologies. In the end, one will be able to identify properly a class of risks that was often incompletely identified or even unidentified before.

The second class gathers all the risks which are indirectly induced by project complexity because of the propagation phenomena within the project complex system as mentioned in section 3 . In other terms, once an exhaustive project risk list is made, there is still some work to be done to identify and assess the risk of a propagation of one of this identified risk within the project system (as well as the underlying risk of positive feedback and amplification through the system). As Heylighen and al. (Heylighen and al., 2006) underline it, "as technological and economic advances make production, transport and communication ever more efficient, we interact with ever more people, organizations, systems and objects". In the case of project management, the main 
consequence is that any change in any component in the project system may thus affect any other component of the project system in an unpredictable way because of change propagation. The two last points besides constitute the body of ongoing publications.

In order to illustrate this issue of complexity driven risks, we now consider an example, the case of an IT development project within the pharmaceutical industry. The main developer (who was temporarily engaged in the project) moved to Germany when development was finished, which broke both organisational (communication, knowledge,...) and technical (IT development tools,...) interfaces within the project. For instance, knowledge and competence loss because of this interface break is an example of complexity directly induced risk. Furthermore, later on, when trying to implement the software that had been developed, it entailed the recourse to an IT firm which had to step back on the software development without any expertise on the subject, which implied complementary work, which implied complementary costs and delays. This illustrates the phenomenon of complexity indirectly induced risks as software development and implementation were connected, etc...

For all practical purposes, the point is that the project complexity framework is not sufficient to identify efficiently complexity induced risks (especially to identify complexity indirectly induced risks) and to quantify them. Notably, there is a crucial need for efficient complexity modelling in order to identify and assess those risks throughout the model. For instance, as Austin and al. (Austin and al., 2002) mention it in the case of design projects, "to achieve anything more than a superficial understanding of the building design process, the complexities of the design activity have to be identified and represented in an appropriate manner", that is to say thanks to an appropriate approach for modelling. That is why we tackle this issue in the following section.

\section{Complexity modelling as an aid for project and risk management}

\section{Objectives of a project complexity model}

As mentioned before, anyone deals with real complexity with the filter of perceived complexity. Our ambition is to elaborate a complexity model that can avoid confusion when dealing with project complexity (partially thanks 
to the project complexity framework we have developed). This model is to encompass all the aspects of project complexity, that is to say project size, project variety, project interactions and elements of context. This model is notably to be used to take up the challenges of complexity and particularly to identify, assess, prevent and/or cure complexity induced risks (of the two classes we defined). Procedures of complexity induced risk management are thus to be elaborated when the final model is built. This section describes the requirements of such a model and describes the model that has been developed thanks to our research works.

\section{Requirements of a good project complexity model}

This paragraph aims at defining the requirements of a good project complexity models: a short synthesis of complex models requirements is to be found at the end of this paragraph in Table II. As underlined by Eppinger and al., "good representations make the important things explicit, expose natural constraints to facilitate computation, are complete, are concise, are transparent to its users and suppress detail when it is not required". (Eppinger and al., 1992) Using this statement as a basis to elaborate an innovative project complexity model helps us to correctly define the scope of this model.

First, the model must make the important aspects of the project system explicit. When referring to the project complexity framework we have built, this means that the model is to explicit all the important elements of the system and their variety, all the important interactions within it and all the important context elements (completeness). On the contrary, everything that does not belong to one of these categories must not be mentioned in the model so that its users feel that the model is strictly related to project complexity (validity and transparency). It must be noted that, as we consider any project as a system, the model is to encompass the four poles of systems analysis.

Moreover, in order to be understood and used easily, the model must suppress unnecessary detail. Indeed, Laurikkala and al. (Laurikkala and al., 2001) argue that modelling at different levels enables one to reduce perceived complexity for all practical purposes since unnecessary guesswork can be considerably reduced. In other terms, a good complexity model should give the possibility for its users to focus more or less on some aspects of the system (suppression of unnecessary detail). The action of modelling is in essence a way to reduce perceived complexity in order to understand it better. 
As a consequence, one should always be aware that there is likely to be an optimal level of complexity for the project models (such as decompositions) used to managed the project (Vidal and al., 2007). Indeed, when they are not complex enough, they are not enough close to reality to give good results even if used properly. On the contrary, when they are too complex, the human ability to deal with complexity is an impassable difficulty and those models cannot be used efficiently by project managers or project team members. For instance, in the case of decomposition, an empirical rule consists in saying that a human brain can analyse until seven children per object within a maximum range of three levels of decomposition. Keeping all these requirements in mind, we have developed an interactions model that enables one to understand, analyse and manage better every aspect of project complexity that is present in the framework we have built.

Table II. Project complexity models requirements

\begin{tabular}{|c|c|}
\hline Complexity theoretical requirements & User requirements \\
\hline Size of the project system & Validity and reliability of the model \\
\hline Variety of the project system & $\begin{array}{c}\text { Intuitiveness and understandability of the } \\
\text { model }\end{array}$ \\
\hline $\begin{array}{c}\text { Interactions and interdependencies within the } \\
\text { system }\end{array}$ & $\begin{array}{c}\text { Suppress unnecessary detail } \\
\text { project system }\end{array}$ \\
\hline $\begin{array}{c}\text { Context and environment dependency of the } \\
\text { Completion and concision of the model } \\
\text { Uncertainties and change propagation as } \\
\text { consequences of complexity }\end{array}$ & Computability of the model \\
\hline
\end{tabular}

Proposition of a complexity model: the ALOE model

A first interactions model (named $3 * 7$ ), notably built thanks to systemics, was elaborated on by Marle (Marle, 2002) and tested in partnership with PSA Peugeot-Citroën. The model gives the possibility for its users to describe the project system by introducing seven kinds of objects which are characterized by seven kinds of attributes (referring to the size of the project system and the variety of its elements). These elements can be interconnected thanks to the use of seven kinds of links (corresponding to the interdependence within the project system). 
When there was sometimes some confusion and lack of agreement on the definition of all the elements that were involved in a project, the $3 * 7$ model gives a general framework and a standardised structure that permits consensus and reality perception sharing within the project team. The model is compatible with other models and tools (WBS, Gantt charts,...) that are global models of a project focusing on one of its dimension (hierarchy, time,...). Its specificity is then to give a better vision at a local level of all the interactions that exist in the environment of any object. Indeed, the $3 * 7$ model makes available all the information about the properties, attributes and interconnected elements of an element of the project system, whatever the nature of the element and the nature of the project are. As a consequence, thanks to this model, one can navigate from an element A of the project system to a neighbour B (connected element), the properties, attributes and internal environment of which are also described thanks to the model.

The $3 * 7$ model proved to be helpful and the industrial added value on the projects was notably to visualise some formerly unformulated information thanks to the identification of the interactions between objects (and therefore of the interrelations between people). For all practical purposes, this permitted notably greater information sharing between project team members (and as a consequence less information loss or alteration). However, we thought that the model could be improved as it did not permit to describe and consider efficiently the project context. In particular, the model structure was not evolutionary enough to reflect the complex dynamics of the project system.

That is why recent research works have leaded us to the elaboration of a complexity model, named ALOE (Attributes, Links, Objects and Events). Some objects, links and attributes definitions have been refined but the greatest difference between the ALOE model and the $3 * 7$ model is the introduction of a new category of elements (events), as shown on Table III. It must be noted that events can be either potential (in which case they are in essence risks) or on the contrary, they can have already occurred. Examples of events can be internal and external decisions, apparition of a new constraint,... Events can have a positive or a negative influence, not only on objects of the system by changing their attributes or by the creation/destruction of new/past objects, but also on links (and their corresponding operators). We finally leave the opportunity for the user to add new events in the system (that spontaneously appear as a consequence of emergence). 
Table III. The ALOE framework

\begin{tabular}{|c|c|c|c|}
\hline Attributes & Links & Objects & Events \\
\hline Quality & Hierarchical Link & Objective & Occurred event \\
\hline Cost & Contribution Link & Deliverable & Potential event \\
\hline (Duration, Start Date) & Sequential Link & Activity & \\
\hline Advancement & Influence Link & Resource & \\
\hline Description & Exchange Link & $\begin{array}{c}\text { Other project within } \\
\text { the firm }\end{array}$ & \\
\hline Allocated resources & & & \\
\hline Added value & & & \\
\hline
\end{tabular}

The ALOE model seems to meet all the requirements we listed to build a good project complexity model. It is complete, as it permits to describe any characteristic of project complexity. Size and variety are mainly described thanks to objects and attributes. Interdependence is mainly described thanks to links and evolving elements of context are for their part mainly described thanks to events and their impact on the evolution of the system. It also encompasses any aspect of systemics (teleological, ontological, functional, genetic). Unnecessary details can be easily suppressed since the user chooses what elements he decides to focus on in the model. Intuitiveness and understanding are finally facilitated thanks to the possibility to navigate from one object to all its neighbours in order to follow easily the propagation of a change caused by an event within the whole system, which cannot be done by the sole human abstraction and understanding of the system. Finally, even though the ALOE model is still to be computed and tested on different projects in order to validate its utilisation and reliability, the industrial tests and applications of the $3 * 7$ model make us confident in the computability and pertinence of the ALOE model.

Research perspectives on the ALOE model

As mentioned hereinbefore, the ALOE model is still to be computed. Moreover, procedures are still to be defined to permit the practical use of the model in order to detect, prevent and/or cure complexity-induced risks (first class and second class). In order to define those procedures, we first aim at understanding better the two classes of complexity induced risks (that are too often neglected in project risk management with the traditional risk analysis and risk response techniques). We are notably presently working on the identification of complexity directly induced risks thanks to the conjoint use of our project complexity framework and of the ALOE model. 
This link between project complexity and risks is to be made thanks to the concept of project vulnerability we are developing. In the end, we hope that the ALOE model will be an innovative tool to assist decision-making when managing complex projects.

\section{Conclusion and final perspectives}

After reviewing the literature on complexity and project complexity, this paper tried to give a better vision of the concept of project complexity, notably thanks to the elaboration of a project complexity standardised framework. This led us to the proposition of a definition of project complexity, the stakes of which were discussed. This whole clarification was helpful to model the project systems and its complexity aspects thanks to a refined interactions model named ALOE that can assist project complexity understanding and management.

Some work is still to be done. First, the ALOE model has to be computed and tested to be finally validated. Furthermore, research works on the formalisation of complexity induced risks are presently being carried out. This complexity-driven approach of project management seems to be a promising approach to assist project management in both academic and industrial environment. As a whole, this approach may lead to the elaboration of complexity-based criteria that could help project scenario selection in the case of project management or that could help project selection in the case of multi-project management.

\section{Acknowledgements}

We would like to thank the project complexity working group of the Industrial Engineering Laboratory of Ecole Centrale Paris for the meetings that have helped us to clarify the concept of project complexity. 


\section{References}

(AFNOR) Norme Afnor FD X 50-118, AFNOR (2007) in Management de Projet - ISBN : 978-2-12-215341-3 Ed. AFNOR

(Aissa, 2004) Aissa A. (2004), Formalisation et quantification de processus de gestion des interactions des projets. Industrial Engineering Masters of Science Thesis, Ecole Centrale Paris, Laboratoire Génie Industriel.

(Austin and al., 2002) Austin S., Newton A., Steele J. and Waskett P. (2002), Modelling and managing project complexity. International Journal of Project Management Vol.20, pp.191-198

(Baccarini, 1996) Baccarini D. (1996), The concept of project complexity - a review, International Journal of Project Management, Vol.14, No. 4, pp. 201-204.

(Boulding, 1956) Boulding K.E. (1956), General systems theory: the skeleton of science. Management science Vol.3 No. 3 pp 197-208.

(Calinescu and al., 1998) Calinescu A., Efstathiou J., Schimand J. and Bermejo J. (1998), Applying and assessing two methods for measuring complexity in manufacturing. Journal of Operational Research Society, Vol. 49, No.7, Intelligent Management Systems in Operations, pp. 723-733.

(Chu and al., 2003) Chu D., Strand R. and Fjelland R. (2003), Theories of complexity - Common denominators of complex systems. Essays \& Commentaries, Complexity, Wiley Periodicals Inc., Vol. 8, No. 3.

(Cicmil and al., 2006) Cicmil S. and Hodgson D. (2006), Making projects critical. Palgrave MacMillan Publishing.

(Corbett and al., 2002) Corbett L.M., Brockelsby J. and Campbell-Hunt C. (2002), Tackling industrial complexity. In G. Friozelle and H. Richards (eds) Cambridge: Institute for Manufacturing, pp.83-96. 
(Edmonds, 1999) Edmonds B. (1999), Syntactic measures of complexity, Thesis of the University of Manchester for the degree of doctor of philosophy in the faculty of arts.

(Eppinger and al., 1992) Eppinger S., Whitney D.E. and Gebala D.A. (1992), Organizing the tasks in complex design projects: development of tools to represent design procedures. NSF Design and Manufacturing Systems Conference, Atlanta GA, pp. 301-309.

(Genelot, 2001) Genelot D. (2001), Manager dans la complexité - Réflexions à l'usage des dirigeants, INSEP Consulting Editions

(Heylighen and al., 2006) Heylighen F., Cilliers P., Gershenson C. (2006), Complexity and Philosophy. Complexity, Science and Society. Ed. Radcliffe.

(IPMA, 2006 a) IPMA - International Project Management Association (2006), IPMA Competence Baseline (ICB). Version 3.0, March 2006, Editor: International Project Management Association.

(IPMA, 2006 b) IPMA (Draft 22.08.2006), Evaluation of project management complexity for IPMA certification process on level $B$.

(Jaafari, 2003) Jaafari A. (2003), Project management in the age of complexity and change. Project Management Journal Vol.34, No. 4, pp. 47-57.

(Koivu and al., 2004) Koivu T., Nummelin J., Tukiainen S., Tainio R. and Atkin B. (2004), Institutional complexity affecting the outcomes of global projects. Published by VTT, VTT Working Papers 14, ISSN 14597683. http://www.vtt.fi/inf/pdf

(Laurikkala and al., 2001) Laurikkala H., Puustiner E., Pajarre E. and Tanskanen K. (2001), Reducing complexity of modelling in large delivery projects, International Conference on Engineering Design, ICED’01, Vol.1, Glasgow, pp.165-172, Professional Engineering Publishing, Bury St Edmunds. 
(Le Moigne, 1990) Le Moigne J.-L. (1990), La théorie du système général. Théorie de la modélisation, Presses Universitaires de France.

(Little, 2005) Little T. (2005), Context Adaptive Agility: Managing Complexity and Uncertainty. IEEE Software, April 2005, Vol. 22, No. 2.

(Marle, 2002) Marle F. (2002), Modèle d'informations et méthodes pour aider à la prise de décision en management de projets, Thèse en Génie Industriel de l'Ecole Centrale Paris.

(Meijer, 2002) Meijer B. (2002), Reducing complexity through organisational structuring in manufacturing and engineering. In Frizelle G \& Richards H (Ed.), Tackling industrial complexity : the ideas that make a difference, pp.183-192. Cambridge: Institute for Manufacturing.

(Millhiser and al., 2007) Millhiser W.P. and Solow D. (2007), How large should a complex system be? An application in organizational teams. Complexity, Vol. 12, Issue 4, pp. 54-70.

(Morel and al., 1999) Morel B. and Ramanujam R. (1999), Through the looking glass of complexity : the dynamics of organizations as adaptive and evolving systems. Organization science Vol.10, No.3, pp.278-293

(Parsons-Hann and al., 2005) Parsons-Hann H., Liu K. (2005), Measuring requirement complexity to increase the probability of project success.

(Penalva, 1997) Penalva J.-M. (1997), La modélisation par les systèmes en situations complexes. Thèse en sciences de Parix XI Orsay préparée au Laboratoire d'Informatique appliquée de Commissariat à l'Energie Atomique.

(Pich and al., 2007) Pich M.T., Loch C.H. and De Meyer A. (2002), On uncertainty, ambiguity, and complexity in project management. Management Science Vol.48, No.8, August 2002, pp 1008-1023. 
(PMI, 2004) PMI - Project Management Institute Standard Committee (2004), A guide to project management body of knowledge (PMBOK). 2004 ed., Newton Square, PA, USA. Project Management Institute.

(Stacey, 2001) Stacey R. (2001), Complex responsive process in organizations: learning and knowledge creation. London, Routledge.

(Rodrigues and al., 1996) Rodrigues A. and Bowers J. (1996), The role of system dynamics in project management. International Journal of Project Management Vol.14, No. 4, pp. 213-220.

(Schlindwein and al., 2005) Schlindwein S. and Ison R. (2005), Human knowing and perceived complexity: implications for systems practice. Emergence: complexity \& organisation Vol. 6, No. 3, pp.19.24

(Sherwood and al., 2005) Sherwood Jones B. and Anderson P. (2005), Diversity as a determinant of system complexity. GIST technical report G 2005-1. $2^{\text {nd }}$ Workshop on complexity in design and engineering.

(Sinha and al., 2001) Sinha S., Thomson A.I. and Kumar B. (2001), A complexity index for the design process, International Conference on Engineering Design, ICED’01, Vol.1, Glasgow, pp.157-163, Professional Engineering Publishing, Bury St Edmunds.

(Vidal and al., 2007) Vidal L.-A., Marle F. and Bocquet J.-C. (2007), Modelling project complexity, International Conference on Engineering Design, ICED’07, Paris.

(Williams, 1999) Williams T.M. (1999), The need for new paradigms for complex projects. International Journal of Project Management, Vol. 17, No. 5, pp 269-273.

(Wood, 2002) Wood M. (2002), Mind the gap? A processual reconsideration of organizational knowledge. Organization, 9(1), pp. 151-171. 